\title{
Effect of Production Systems for Laying Hens on Hen Welfare
}

\author{
Brian Tainika ${ }^{1, a, *}$, Ahmet Şekeroğlu ${ }^{1, b}$ \\ ${ }^{I}$ Department of Animal Production and Technologies, Faculty of Agricultural sciences and Technologies, Niğde Ömer Halisdemir \\ University, 51200 Niğde, Turkey
}

*Corresponding author

\begin{tabular}{l|l}
\hline A R T I C LE IN F O & A B S T R A C T \\
\hline & This review article discussed the effects of various production systems on the welfare of laying hens.
\end{tabular}

Review Article The global egg production capacity has been increasing with the evolving production systems which are driven by the consumer preferences. In developed countries, the egg industry has shifted from focusing on quantity and quality of eggs to asking questions of how these eggs are produced. Animal

Received : 11/12/2019

Accepted : 03/01/2020 welfare issues emphasized by consumers in these countries led to the banning of conventional cages
as seen by European Union in 2012 . Such legal measures have uplifted research in various alternative
production systems which are thought to be animal friendly. Countries that have adjusted to
alternative systems such as free range are registering an increase in the number of free range eggs
which is a positive sign for an industry that is willing to adapt and move forward. However, in
developing countries, conventional cages are still being used because they are fundamental to the
quantity of egg production which is a success indicator of the egg industry. In addition, lack of
awareness within the consumers and local producers that birds are sentient has not helped the poultry
industry in such countries. However, the alternative production systems have also not fulfilled all
the behavioural needs of the animals and, hen welfare issues such as keel and bone damage are
common in enriched and perched systems. Also, the high prevalence of diseases and parasites are
observed with significant levels in litter floor and outdoor systems an issue attributable to the direct
contact between birds and soil or faces. Due to the continuing welfare issues in all laying hen
production systems, it is suggested that in addition to genetic selection for traits like bone strength,
reduced feather pecking, research should combine both the modification of equipment's or materials
used in each production system and environmental factors such as illumination and temperature as
an alternative to improve hen welfare.

Keywords: Production system Laying hen Hen welfare Behaviour Performance

common in enriched and perched systems. Also, the high prevalence of diseases and parasites are
observed with significant levels in litter floor and outdoor systems an issue attributable to the direct
contact between birds and soil or faces. Due to the continuing welfare issues in all laying hen
production systems, it is suggested that in addition to genetic selection for traits like bone strength,
reduced feather pecking, research should combine both the modification of equipment's or materials
used in each production system and environmental factors such as illumination and temperature as
an alternative to improve hen welfare.

tainika2012b@yahoo.com (iD) https://orcid.org/0000-0001-6785-4324 | ${ }^{\mathbf{D}} @$ ahmet.sekeroglu@ohu.edu.tr (iD https://orcid.org/0000-0002-1896-2449

This work is licensed under Creative Commons Attribution 4.0 International License

\section{Introduction}

From the 1950s, egg production systems of laying hens have undergone remarkable changes which have affected hen behaviour and welfare such as feather pecking, cannibalism, bone disorders, floor eggs and performance in terms of quality and total number of eggs produced (Nys et al, 2011). Using United States egg production industry as a case study, Sandilands and Hocking, (2012) noted that in 1920s a few number of hens were reared backyard by the farmer to obtain eggs for family consumption and other domestic use. Thereafter, local shops and market emerged for egg supply and, flock size increased as egg production became more profitable and, in the 1960s, poultry production in United States had highly improved with increased flock size and birds kept in conventional cages due to hygienic and economic issues. In most of European countries, confinement of birds as it is seen in battery cage system became a public issue after a publication "Animal Machines" by Ruth Harrison in 1964 since it was below the minimum standards of the bird's freedom to arise, rest, change direction, preening, and limb stretching (Appleby, 2003). It was further emphasized that the system was against the five animal freedoms which include; freedom from (i) hunger and thirst through enabling availability of clean water twenty hours per day and a quality or balanced ratio that maintains health and liveliness, (ii) discomfort by provision of an appropriate surrounding, (iii) pain, injury and disease which is achieved by prevention or diagnosis and treatment which is fast, (iv) freedom to express normal behaviour by allowing enough distance, proper materials or equipment and appropriate animal grouping and, (v) fear and distress via appropriate environment and handling that does not cause mental suffering (Webster, 2001). As a result, alternative rearing systems were introduced, animal rights and protection laws were reviewed and the agriculture sector had to abide by them due to public pressure. In between 1970 and 1990 with the help of 
national governments and some animal welfare groups, most of the focus was on the alternative systems to cages and these included; deep litter, straw yards, and free range in the United Kingdom, adoption of slatted floors in Denmark and use of tiered wire floors in Germany (Appleby, 2003). Due to the legal banning of conventional cage system by European Union (EU) in 2012, changes in the way of rearing layers and so many emerging housing systems occurred. The production systems for egg laying hens have been defined as non cage systems and enriched systems by EU. The non cage systems include; floor system where birds are kept on the floor of the building with nest boxes which are connected to an automatic egg collection system and aviaries system is also a non cage similar to floor system but having many tiered platforms allowing the hens to utilize the height of the building. This increases stocking density which is economical to the producer. It is known that modification of this system allows the producer to keep hens in a semi enclosed or covered outdoor space or under free range, either part of the day or full day. Hens kept under free range should be sheltered at night and from adverse environmental conditions like winter (Mench et al., 2011). Enriched cage system is a modification of conventional cage system with perches, area for nesting and designed materials to cater for foraging and dust bathing behaviours (Directive, EU. 1999). Research in the housing system as well as management practices will continue to be of great importance since the non cage systems also have a welfare problem of cannibalism. The use of beak trimming to control cannibalism is very complex and it's known to alter the bird's behaviour of feeding, preening and among others. De Boer and Cornelissen, (2002) confirmed an approach that uses sustainability indicators to compare egg laying production systems. They concluded that aviary system is more friendly to animals compared to battery cage system. With this information, a worldwide improvement can be achieved in terms of hen welfare. Sandilands et al. (2009) suggested that non cage systems with perches are associated with high outbreaks of bone fractures which is a sign that modern layers are not better suited to systems with perches. In many parts of the world conventional cage system is the most used commercial housing system for egg production due to its economic performance. It is stated that over $95 \%$ of the egg laying hens are kept in battery cages in countries outside European Union (Mench et al., 2011). However, in some countries pressure from Animal welfare activists is trying to drive the poultry sector away from conventional cage system to alternative production systems (Shini et al., 2019). Welfare assessment in egg production systems has been under constant improvement and development because it is not an easy process and many factors have to be considered. An example of such recent developments is the computer based model fowl welfare (FOWEL) that analyses production system as input and welfare as output (De Molet al., 2006). Lay et al. (2009) argued that every egg production system has its own limitations in relation to welfare and, through selection for welfare traits like strength of the bone, reduced feather peaking and cannibalism is one of the ways to improve hen welfare. In addition to the above brief historical background of the development of poultry egg production systems in some countries, the aim of this study is to review the effects of the poultry egg production systems on hen welfare by focusing on hen health, hen production and hen behaviour issues.

\section{Hen Health Issues}

In modern poultry production, many health problems that are associated to the laying hen housing systems are limiting factors not only to the wellbeing of the birds but also the number of eggs laid. Some of these issues are discussed below from the one thought to be the most significant.

\section{Bone and Keel Bone Disorders}

Bone and keel bone disorders are widely known welfare concerns affecting the egg industry. These disorders include; bone breakage, fractures, distortions and deviations and bone fragility. Various studies have reported that breaking vigour of the tibia and humerus bones is higher in enriched cages compared to conventional cage system (Freire et al., 2003; Vits et al., 2005; Jendral et al., 2008, Barnett et al., 2009; Tactacan et al., 2009; Li et al., 2019). They suggested that installation of perches enables the birds to exercise and strengthen their bones while lack of exercise or activity in conventional cages leads to excessive bone mineral loss. Keel bone damage is another important welfare and health issue in commercial egg industry that is known to cause problems connected to limited utilization of perches and nest boxes and lack of locomotion or reduced activity. Birds do not have diaphragm and depend on the movement of the keel bone and ribs for the respiration process. Therefore, damage of the keel results into pain and physical limitation of motion which affects the metabolic and thermoregulatory mechanisms of the birds by impairing respiration (Riber et al., 2018). Several studies have stated that the level of keel bone disorders are more prevalent in furnished cage (33\%) (Vits et al., 2005) and, perchery or aviary systems (73\%) (Freire et al., 2003) as compared to battery cage and other systems. They emphasized that this was due to excessive use of perches as well as falls from poor landing on the perches and collisions with the perches. The use of soft perch material has been proposed to reduce keel bone injuries. A study by Stratmann et al. (2015) evaluated the effectiveness of covering metal perches with a soft polyurethane material over keel bone damage. They found that pens installed with soft perch materials had low number of hens with keel bone fractures and deviations. It was concluded that soft material lowers the kinetic energy and accelerates the transmission of pressure on the keel bone during landing and perching. The comparison of the welfare of layer hen in four housing systems in the United Kingdom was carried out by Sherwin et al. (2010). They confirmed that $56 \%$ of the total number of hens in a flock experienced a fracture and, old fractures accounted for $85 \%$ of the total fractures while $47 \%$ of the total number of hens experienced keel breakages during the egg laying cycle. Additionally, they reported that fresh keel bone fractures are five times higher in battery cage system than in free range, barn and enriched cage system. They associated such breakages to poor depopulation and handling and, most importantly osteoporosis due to lack or limited activity in battery cage system. 


\section{Mortality}

Mortality is one of the known indicators for poultry welfare and high mortality rate shows poor welfare. Fossum et al. (2009) compared the common roots of death in various housing systems of necropsied laying hens in Sweden. The results indicated that outbreaks of diseases as a result of bacteria and parasites and cannibalism was high in hens reared under litter based and free range systems as compared to cages. This was linked to the fact that hens in these systems are directly associated with litter, soil and fecal materials which harbours microorganisms. Furthermore, it is known that the stocking density of birds in litter floor and free range systems is also high and, this could be the reason why cannibalism is also higher than in caged systems. The bacterial egg shell contamination in battery and enriched cages and aviary systems was evaluated by De Reu et al. (2005). They reported higher dust and bacterial air contamination $\left(>5.3 \log \mathrm{cfu} / \mathrm{m}^{3}\right)$ in the aviary system in relation to cage systems. They argued that factors such as bird, waste products, feeds, litter materials, floor materials and soil are the chief source of dust in the poultry house. In addition, the level of dust or air contamination is proportional to the level of microbial contamination in the poultry house because dust is known to carry microorganisms such as bacteria.

\section{Cage Layer Fatigue}

This is a generally known problem that is associated to cage production system and high egg production that depletes the skeletal system. The prevalence rate of cage layer fatigue can reach as high as $20 \%$. The affected birds become so weak due to fragile thin bones, experience muscular paralysis and finally die due to dehydration and starvation since they are unable to stand (Grumbles, 1959). It has been demonstrated that around $85 \%$ of the affected hens can recover from the disease if they are removed from cages and reared under floor system within a week. It is known that this technique is based on the fact that cage layer fatigue is associated with osteoporosis and, allowing affected birds to exercise by walking around can improve their bone strength and volume which reduces its effects. Additionally, nutritional deficiencies such as lack or low levels of calcium and phosphorous can trigger this condition because these nutrients have a high influence on the metabolic and physiological processes in relation to skeletal system (Grumbles, 1959).

\section{Fatty Liver Haemorrhagic Syndrome}

This is another health issue that is highly prevalent in cages. It is known that in healthy hens which are in a high egg production cycle, mortality rate as a result of this disease can reach over $5 \%$. To evaluate fatty liver haemorrhagic syndrome, surveys were conducted with cage and alternative production systems and three commercial cage farms in Queensland were monitored for three months by Shini et al. (2019). It was showed that $40 \%$ of 600 necropsied hens died as a result of fatty liver haemorrhagic syndrome and the prevalence of this condition was more common in heavier birds as compared to the lighter birds. Furthermore, the disease was also associated with management practices such as limited movement, high levels of production and fluctuations in temperature. Julian, (2005) concluded that the disease is more prevalent in birds reared in hot environments and under high energy diets since these factors are known to affect hepatic lipid metabolism and expose birds to fatty liver haemorrhagic syndrome.

\section{Hen Production Issues}

The egg poultry production systems are known to differ in a number of production aspects such as total egg production per laying cycle, egg quality, stress levels and among others. These issues have been highlighted in relation to the production systems from what is thought to be of the greatest importance in measuring welfare.

\section{Egg Production and Egg Quality}

Egg production is known to be an important indicator of hen welfare in poultry production. The enrichment in both cage and non cage systems with perches has been shown to have both positive and negative impacts on hens during the production life. Perches play a vital role as a cooling media in combating the negative impacts of high temperatures during summer on layers (Strong et al., 2015). This is based on the fact that around $20 \%$ of the hens body heat can be emitted through the bird's feet which is ensured by a special organ of the arteriovenous anastomose system. Likewise, the body heat of the bird can easily be transferred to the cooled perches as they roost (Hu et al., 2019 as cited from Hilman and Scott, 1989). In a comparison study between cooled and air perches, it was revealed that hens from cages with cooled perches had increased egg production, body weight gains, egg mass, egg shell quality traits and low mortality. It was suggested that the water chilled perches can alleviate the effects of heat on the above production performances during hot summers. They concluded that installation of cooled perches in poultry cages maintains the bird's thermoregulation throughout the daily cyclic heat series of $35^{\circ} \mathrm{C}$ (Hu et al., 2019). Pavlik et al. (2008) compared three housing technologies for egg production. It was reported that the intensity of egg production was lower in hens under deep litter system than in standard cage and enriched conditions. This was linked to high levels of stress and more activity in the deep litter technology. A study by Ahammed et al. (2014) found that there was no significance difference for the hen day egg production between aviary, barn and conventional cage production system. However, it was noted that the external egg quality (dirty and cracked eggs) deteriorated more in the barn system as compared to other systems under the study. Hens housed in barns have been identified to have so many eggs with blood stains as compared to free range, battery cage and furnished cage systems (Sherwin et al., 2010). Staining of the eggshell with blood is known to occur as a result of various factors including; laying too large eggs which tears the cloaca, prolapse, disease or vent pecking. Galic et al. (2019) compared the egg quality of Hisex hens kept under furnished cage, aviary and free range system. They showed that eggs from hens in enriched cages were larger and heavier than those from the rest of the systems. Other parameters such as yolk percentage $(26 \%)$ and yolk to albumen ratio (0.427) were higher from free range eggs. The evaluation of egg shell quality demonstrated that hens from furnished cages laid eggs with the thickest shells, 
highest shell strength and needed much force to be broken $(44.14 \mathrm{~N})$. This is $12 \%$ and $17 \%$ greater than the average force applied to break eggs from free range $(39.37 \mathrm{~N})$ and aviary $(37.68 \mathrm{~N})$ systems respectively.

\section{Body Weight}

Body weight of the animal is a known parameter used to show that animal welfare and health have been compromised. Sherwin et al., (2010) assessed the body weight and keel protrusion as indicators of emaciation which is a sign of poor welfare. It was found that hens housed in barns were lighter at post mortem and possessed the highest severe keel protrusion. On the other hand, hens from conventional cage system were fleshy at post mortem and had reduced serious keel protrusion. Pavlik et al. (2008) stated that hens from the standard cage system weighed more compared to those from enriched conditions at 75 week of age. Li et al. (2019) concluded that use of cages of dimensions $160 \times 160 \times 62 \mathrm{~cm}$ boosts body weight gain, improves shank length as well as decreasing the average quantity of feed consumed per day of hens from 418 week of age.

\section{Stress}

Stress is generally known to provide scientific measurements of animal welfare. The welfare of laying hens in 4 production systems in the United Kingdom was compared by Sherwin et al. (2010). It was shown that hens from barn system have the highest fecal corticosterone levels compared to battery cage, free range and furnished cage systems. This indicates that the system is more stressful to the birds. In addition, the proportion of eggshells with calcification spots in barn eggs was affirmed to be four times higher than for hens housed in furnished cages. This was linked to the fact that birds that are stressed during the laying period will have delayed oviposition leading to additional deposition of calcium carbonate on to the egg. Pavlik et al. (2008) assessed three housing systems (standard cage, enriched and deep litter system) and plasma corticosterone levels of laying hens. Their study shown that the plasma corticosterone levels were highly elevated till 75 week of age in hens under deep litter conditions. The effects of cage size on growth performance, blood biochemistry, and antibody response in layer breeder males during rearing stage were assessed by $\mathrm{Li}$ et al. (2019). It was confirmed that plasma corticosterone was lower in birds reared in large cages $(160 \times 160 \times 62 \mathrm{~cm})$ as compared to those kept under small cages. This reaffirmed that ensuring large space to the birds increases their movement and the use of space which reduces stress and it is known that plasma corticosterone signals the level of stress and fear.

\section{Feather Loss and Damage}

Feathers are known to be essential in the thermoregulation mechanism of birds and their protection from injuries as well as a physical barrier of some infections. Generally, a good feather cover is known to be economical to producers and has significant benefits to the hen's welfare. This is because when birds lose feathers, their body heat loss is increased and in turn it increases the bird's metabolic rate in order to maintain its body temperature. In this situation, feed consumption is elevated to enable the bird maintain its energy needs. Another known critical point of feather deterioration is the triggering of injurious feather pecking and cannibalism which increases chicken mortality in the poultry house. Hen production systems is commonly known as one of the factors that affect feather cover on top of factors like type of the material used in pens and the age of birds. Decina et al. (2019) conducted a survey focused on housing and management techniques and their association with feather damage in 122 furnished cage farms in Canada. It was shown that feather damage resulting from feather pecking is determined by many factors and increases as the bird ages. Furthermore, it was concluded that the colour of the feathers, feeding in the midnight, availability and no presence of scratch area or enriched material have significant effects on feather damage. Sewwandi et al. (2018) scored the feathers at the back, wing and neck of birds from two floor (litter and slatted) systems and they concluded that slatted floors reduce feather loss as compared to litter floor. However, both systems significantly $(\mathrm{P}<0.05)$ affect feather score at the back, wing and neck. Also, when different light sources in the cage system were investigated, it was suggested that monochromatic light in pens provides a better mean body feather score in birds reared in bottom tier of the four tiered cage in enriched cage system (Tünaydin and Dikmen, 2019). The lower feather deterioration was associated to light emitting diodes having a calming effect on the birds making them less aggressive. Shi et al. (2019) experimented the effect of 3 types of CADs (abrasive strips, metal plates with holes, and rubber mats with grooves) on claw condition, fear, stress and plumage condition of laying hen breeders. Installation of claw abrasive devices (CADs) in cages was suggested to have a positive effect on feather condition by reducing plumage damage. This was connected to provision of CADs being a form of environmental cage enrichment which enables fulfillment of the hen's need to wear its claws. Also, CADs offered hens an alternative for investigative behaviour which reduced injurious behaviours and ensured good skin and plumage condition.

\section{Litter Management}

Litter management is also a vital concern in layer production due to its relationship to hen welfare and performance. Allowing hens full or partial litter access has created opposite views in poultry production. Oliveira et al. (2018) evaluated the effects of litter floor access in different housing systems on litter condition and hen welfare. They concluded that allowing hens partial litter access is beneficial in terms of lowering the ammonia levels due to lack of wet litter and reduction of manure deposition on the floor.

\section{Behavioural Performance Issues}

Behaviour is known to show the welfare status of animals at a given time and it is allied to both the physiological and the environmental factors. The modern poultry industry is affected by many abnormal behaviours which are known to result from failure of birds to adapt to a given environment. These behaviours in relation to the various production systems are discussed below. 


\section{Cannibalism, Injurious Peaks and Feather Pecking}

The egg production sector has always encountered welfare and heathy challenges due to cannibalism, pecks that result into injuries and feather peaking. It is known that these three problems are seen in all the egg laying production systems although the degree of occurrence is lower in cage systems. The variation in the prevalence is related to the number of hens kept per square meter or group size. Cage systems are known to manage small numbers of birds as compared to non cage systems. In across sectional study of the occurrence of feather pecking in laying hens in alternative production systems and it's relationship with management and disease carried out by Green et al. (2000), it was reported that lack of loose litter materials in indoor systems increases feather pecking. Also, poor litter quality had a negative effect on foraging and dust bathing behaviours and accelerated the prevalence of feather pecking of individual birds. However, systems with outdoor space were suggested to offer a number of pecking opportunities which encourages foraging and a reduction in feather pecking tendency. Sherwin et al. (2010) studied the welfare of hens in four housing systems in UK. They observed that gentle feather pecking was highest in free range system but, few birds had damaged feathers and feather damage score was low. However, free range system had the highest prevalence of vent pecking two times greater than conventional, barn and furnished cage systems. This was affiliated to high degree of movement and positioning of perches increasing susceptibility of the vent for this behaviour. Moreover, severe feather pecking was stated to be highest in the hens housed in barns and, because birds are not given an alternative to peck at, barn system had the highest plumage damage score and many hens with damaged feathers. It was concluded that hens reared under deep litter conditions spend more time moving, scratching and dust bathing, birds in the standard cage environment most of their time is spent on feeding, aggression was lower in birds housed in enriched cages and increased in hens under deep litter system. Furthermore, unavailability of litter or perches was the identified reason for lack of activity in standard cage system and hens are only left with one option and, that is feeding. Cordiner and Savory, (2001) studied the use of perches and nest boxes in relation to social dominance. It was revealed that providing perches helped to reduce aggressive peaks and this was significant when high perches (three parallel perches in a 458A frame, one $70 \mathrm{~cm}$ and two $35 \mathrm{~cm}$ high) were used. Shi et al. (2019) investigated the effect of the size of nest boxes and various claw abrasive devices in cages. They recommended that installation of both nest boxes and CADs can offer environmental needs that reduce feather pecking but, use of large nests with dimensions of $0.90 \mathrm{~m} \times 0.40 \mathrm{~m} \times 0.60 \mathrm{~m}$ and abrasive strips is more beneficial.

\section{Comfort Behaviour}

Due to inadequate social space in battery cage systems, hens cannot perform the vital behaviours for body maintenance and care of the feathers. These include; stretching, wing flapping, body shaking and preening which are comfort behaviours (Pavlık et al., 2008). Perches are known to enable the birds express comfort behaviours such as roosting and promote bone strength. Nevertheless, during the setting up of perches in the poultry houses, perch length and height should be seriously considered. Birds prefer perches which are high within the tier and this enables the fulfillment of the perching and other related behaviours to perching (Brendler and Schrader, 2016).

\section{Floor Eggs}

Floor eggs is another common challenge facing the egg industry due to higher level of contamination, reduced hatchability and chick quality. Floor eggs is also known as a signal of failure of a hen to express her reproduction behaviour (oviposition). Gunnarsson, (1999) analysed the rearing conditions of 59 commercial house flocks in Sweden. It was confirmed that the ability of the birds to reach to perches before 4 weeks of age reduces the occurrence of number of eggs laid on the floor during the initial production stage. Besides, the outbreak of vent cannibalism throughout the entire production cycle decreased. This reduction was related to perches enabling the hens learn easily to access the laying nests and escape from aggressive mates. Oliveira et al. (2018) concluded that use of partial litter access as a modification of aviary production system lowers the occurrence of floor eggs as compared to full litter access. Modification of multi tier system with structural facilities such as ramps has been stated to have a positive impact on behaviour and production of birds. Zheng et al. (2019) compared ramps and ladders in a multi tier system with perches in terms of bird behaviour and production. It was observed that the number of eggs laid on the floor was reduced in pens with ramps but, the angle of the ramps was less than $40^{\circ}$ for better results. Also, it was concluded that ramps enable the birds to adapt early which ensures effective use of space and facilities such as nest boxes within the pens especially in battery cages.

\section{Conclusions}

In general, modifications of the production systems in relation to the equipment seems to be beneficial to improve the behaviour of hens and its welfare. Since the environmental factors like temperature and light influences the production system, research should try to combine both the production systems and modification of equipment or materials used in each production system and, some of these factors to ensure forward developments in welfare.

\section{Acknowledgments}

The authors gratefully acknowledge Mr. Francis Taingzunaaloung for the enormous contribution towards proof reading on this paper.

\section{References}

Ahammed M, Chae BJ, Lohakare JD, Keohavong B, Lee MH, Lee SJ, Ohh SJ. 2014. Comparison of aviary, barn and conventional cage raising of chickens on laying performance and egg quality. Asian-Australasian Journal of Animal Sciences, 27(8): 1196-1203 DOI: 10.5713/ajas.2013.13394.

Appleby MC. 2003. The European Union ban on conventional cages for laying hens: History and prospects. Journal of Applied Animal Welfare Science, 6(2): 103-121. DOI: 10.1207/S15327604JAWS0602_03. 
Barnett JL, Tauson R, Downing JA, Janardhana V, Lowenthal JW, Butler KL, Cronin GM. 2009. The effects of a perch, dust bath, and nest box, either alone or in combination as used in furnished cages, on the welfare of laying hens. Poultry Science, 88(3): 456-470. DOI: 10.3382/ps.2008-00168.

Brendler C, Schrader L. 2016. Perch use by laying hens in aviary systems. Applied Animal Behaviour Science, 182: 9-14.

Cordiner LS, Savory CJ. 2001. Use of perches and nestboxes by laying hens in relation to social status, based on examination of consistency of ranking orders and frequency of interaction. Applied Animal Behaviour Science, 71(4): 305317. DOI: 10.1016/S0168-1591(00)00186-6.

De Boer IJM, Cornelissen AMG. 2002. A method using sustainability indicators to compare conventional and animalfriendly egg production systems. Poultry Science, 81(2): 173-181. DOI: 10.1093/ps/81.2.173.

De Mol RM, Schouten WGP, Evers E, Drost H, Houwers HWJ, Smits AC. 2006. A computer model for welfare assessment of poultry production systems for laying hens. NJAS Wageningen Journal of Life Sciences, 54(2): 157-168. DOI: 10.1016/S1573-5214(06)80019-9.

De Reu K, Grijspeerdt K, Heyndrickx M, Zoons J, De Baere K, Uyttendaele M, Herman L. 2005. Bacterial eggshell contamination in conventional cages, furnished cages and aviary housing systems for laying hens. British Poultry Science, 46(2): 149-155. DOI: $10.1080 / 00071660500065359$.

Decina C, Berke O, van Staaveren N, Baes CF, Widowski TM, Harlander-Matauschek A. 2019. An investigation of associations between management and feather damage in Canadian laying hens housed in furnished cages. Animals, 9(4): 135. DOI: $10.3390 /$ ani9040135.

Directive EU. 1999. Council Directive 99/74/EC of 19 July 1999 laying down minimum standards for the protection of laying hens. Official journal of the European Communities, 203: 5357.

Fossum O, Jansson DS, Etterlin PE, Vågsholm I. 2009. Causes of mortality in laying hens in different housing systems in 2001 to 2004. Acta Veterinaria Scandinavica, 51(1): 3. DOI: 10.1186/1751-0147-51-3.

Freire R, Wilkins LJ, Short F, Nicol CJ. 2003. Behaviour and welfare of individual laying hens in a non-cage system. British Poultry Science, 44(1): 22-29. DOI: 10.1080/0007166031000085391.

Galic A, Filipovic D, Janjecic Z, Bedekovic D, Kovacev I, Copec K, Pliestic S. 2019. Physical and mechanical characteristics of Hisex Brown hen eggs from three different housing systems. South African Journal of Animal Science, 49(3): 468-476.

Green LE, Lewis K, Kimpton A, Nicol CJ. 2000. Cross-sectional study of the prevalence of feather pecking in laying hens in alternative systems and its associations with management and disease. Veterinary Record, 147(9): 233-238.

Grumbles LC. 1959. Cage layer fatigue (Cage Paralysis). Avian Diseases, 3(2): 122-125. DOI: 10.2307/1587714.

Gunnarsson S. 1999. Effect of rearing factors on the prevalence of floor eggs, cloacal cannibalism and feather pecking in commercial flocks of loose housed laying hens. British poultry science, $40(1): 12-18$.

Hu JY, Hester PY, Makagon MM, Xiong Y, Gates RS,Cheng HW. 2019. Effect of cooled perches on performance, plumage condition, and foot health of caged White Leghorn hens exposed to cyclic heat. Poultry Science, 98(7): 27052718. DOI: $10.3382 / \mathrm{ps} / \mathrm{pez} 039$.

Jendral MJ, Korver DR, Church JS, Feddes JJR. 2008. Bone mineral density and breaking strength of white leghorns housed in conventional, modified, and commercially available colony battery cages. Poultry science, 87(5): 828837.
Julian RJ. 2005. Production and growth related disorders and other metabolic diseases of poultry-a review. The Veterinary Journal, 169(3): 350-369. DOI: 10.1016/j.tvj1.2004.04.015.

Lay DC, Fulton RM, Hester PY, Karcher DM, Kjaer JB, Mench JA, Porter RE. 2011. Hen welfare in different housing systems. Poultry Science, 90(1): 278-294. DOI: 10.3382/ps.2010-00962.

Li JY, Liu W, Ma RY, Li Y, Liu Y, Qi RR, Zhan K. 2019. Effects of cage size on growth performance, blood biochemistry, and antibody response in layer breeder males during rearing stage. Poultry Science, 98(9): 3571-3577. DOI: 10.3382/ps/pez102.

Mench JA, Sumner DA, Rosen-Molina JT. 2011. Sustainability of egg production in the United States, The policy and market context. Poultry Science, 90(1): 229-240. DOI: 10.3382/ps.2010-00844.

Nys Y, Bain M, Immerseel FV. 2011. Improving the safety and quality of eggs and egg products. Volume 1.., Cambridge, United Kingdom: Woodhead publishing limited. ISBN 9780-85709-391-2.

Oliveira JL, Xin H, Chai L, Millman ST. 2018. Effects of litter floor access and inclusion of experienced hens in aviary housing on floor eggs, litter condition, air quality, and hen welfare. Poultry Science, 98(4): 1664-1677. DOI: $10.3382 / \mathrm{ps} /$ pey525.

Pavlik A, Jezova D, Zapletal D, Bakos J, Jelinek P. 2008. Impact of housing technology on blood plasma corticosterone levels in laying hens. Acta Veterinaria Hungarica, 56(4): 515-527. DOI: 10.1556/AVet.56.2008.4.9.

Riber AB, Casey-Trott TM, Herskin MS. 2018. The influence of keel bone damage on welfare of laying hens. Frontiers in veterinary science, $5: 6$.

Sandilands V, Hocking PM. 2012. Alternative systems for poultry: Health, welfare and productivity. Vol. 30., Cambridge, USA: CABI. ISBN-13: 978-1-84593-8246.

Sandilands V, Moinard C, Sparks NHC. 2009. Providing laying hens with perches: Fulfilling behavioural needs but causing injury. British Poultry Science, 50(4): 395-406.

Sewwandi PVD, Mutucumarana RK, Iddamalgoda A. 2019. Effects of different floor systems and the bird's age on body weight gain and feather score of broiler breeder hens. Journal of Agricultural Sciences - Sri Lanka, 14(1): 49. DOI: 10.4038/jas.v14i1.8456.

Sherwin CM, Richards GJ, Nicol CJ. 2010. Comparison of the welfare of layer hens in 4 housing systems in the UK. British Poultry Science, 51(4): 488-499. DOI: $10.1080 / 00071668.2010 .502518$.

Shi H, Li B, Tong Q, Zheng W. 2019. Effects of different clawshortening devices on claw condition, fear, stress, and feather coverage of layer breeders. Poultry Science, 98(8): 31033113. DOI: $10.3382 / \mathrm{ps} / \mathrm{pez} 083$.

Shi H, Li B, Tong Q, Zheng W, Feng G. 2019. Influence of nest boxes and claw abrasive devices on feather pecking and the fear responses of layer breeders in natural mating colony cages. Applied Animal Behaviour Science, 220: 104842. DOI: $10.1016 / j$.applanim.2019.104842.

Shini A, Shini S, Bryden WL. 2019. Fatty liver haemorrhagic syndrome occurrence in laying hens: impact of production system. Avian pathology, 48(1): 25-34. DOI: 10.1080/03079457.2018.1538550.

Stratmann A, Fröhlich EKF, Harlander-Matauschek A, Schrader L, Toscano MJ, Würbel H, Gebhardt-Henrich SG. 2015. Soft perches in an aviary system reduce incidence of keel bone damage in laying hens. Plos one, 10(3): e0122568. DOI: 10.1371/journal.pone.0122568.

Strong RA, Hester PY, Eicher SD, Hu J, Cheng HW. 2015. The effect of cooled perches on immunological parameters of caged white leghorn hens during the hot summer months. Plos one, 10(10): e0141215. DOI: 10.1371/journal.pone.0141215. 
Tactacan GB, Guenter W, Lewis NJ, Rodriguez-Lecompte JC, House JD. 2009. Performance and welfare of laying hens in conventional and enriched cages. Poultry Science, 88(4): 698-707. DOI: 10.3382/ps.2008-00369.

Tünaydin G, Dikmen BY. 2019. Impact of light-emitting diode and compact fluorescent lighting type and cage tier on layers reared in an enriched cage system, part 2: Some welfare traits. Turk J Vet Anim Sci, 43: 627-635. DOI: 10.3906/vet-190375.

Vits A, Weitzenbürger D, Hamann H, Distl O. 2005. Production, egg quality, bone strength, claw length, and keel bone deformities of laying hens housed in furnished cages with different group sizes. Poultry science, 84(10): 1511-1519.
Webster AJ. 2001. Farm animal welfare: the five freedoms and the free market. The veterinary journal, 161(3): 229-237. DOI: $10.1053 /$ tvjl.2000.0563.

Zheng H, Li B, Tong Q, Chen G, Li X. 2019. Modification of perchery system: Preference for ramps rather than ladders during early adaptation period for cage-reared pullets. International Journal of Agricultural and Biological Engineering, 12(4): 34-42. DOI: 10.25165/j.ijabe.20191204. 4030. 